\title{
Hydrothermal Formation of Tungsten Trioxide Nanowire Networks on Seed-Free Substrates and Their Properties in Electrochromic Device
}

\author{
Chung Jung Hung, Yi Hsuan Huang, Chih Hao Chen, Pang Lin, and Tseung Yuen Tseng, Fellow, IEEE
}

\begin{abstract}
Facile and cost-efficient hydrothermally grown 3-D tungsten trioxide $\left(\mathrm{WO}_{3}\right)$ nanowires (NWs) network film on seedfree fluorine-doped tin oxide (FTO) substrates without using additive or capping agent is reported. The NW networks are hexagonal phase and the morphologies are changed by adjusting the pH of precursor solutions. Growth mechanism of $\mathrm{WO}_{3} \mathrm{NWs}$ is also extensively discussed. The designed porous film exhibits remarkable enhancement of the electrochromic (EC) properties. In particular, a significant optical modulation $(57 \%$ at $632 \mathrm{~nm})$, fast color switching speed (bleaching: $7 \mathrm{~s}$ and coloration: $21 \mathrm{~s}$ ), high coloration efficiency $\left(120.3 \mathrm{~cm}^{2} \mathrm{C}^{-1}\right.$ at $\left.632 \mathrm{~nm}\right)$, high $\mathrm{Li}^{+}$ diffusion coefficient $\left(2.14 \times 10^{-9} \mathrm{~cm}^{2} \mathrm{~s}^{-1}\right)$, and excellent cycling stability (87\% after 1000 cycles) are achieved for the 3-D NWs film. The improved EC properties are mainly attributed to the highly porous film, which makes the $\mathrm{Li}^{+}$diffusion becomes easier and provides larger specific surface area for chargetransfer reactions. Furthermore, we also reported an EC device $(50 \mathrm{~mm} \times 50 \mathrm{~mm})$ with a simple two-electrode configuration showing high optical contrast. The 3-D $\mathrm{WO}_{3} \mathrm{NWs}$ network film acts as an excellent EC material.
\end{abstract}

Index Terms-Electrochromic device, growth mechanism, nanowire, tungsten trioxide.

\section{INTRODUCTION}

$\mathbf{R}$ ECENTLY, the worldwide shortage of oil has led to the rapid rise of energy prices. Learning how to conserve energy is one of the most important issues. Nowadays, most of the people often spend a lot of time staying in the house. In order to maintain the indoor environment comfortable, energy consumption is gradually increasing. To date, switchable electrochromic (EC) windows have been widely projected to significantly reduce the energy use of buildings [1]. Under a small applied voltages, the EC window can reversibly change their optical characteristics (i.e., coloration, transmittance),

Manuscript received September 5, 2013; revised December 31, 2013; accepted January 8, 2014. Date of publication January 27, 2014; date of current version May 1, 2014. This work was supported by the National Science Council of Taiwan under Contract NSC 102-2623-E-009-006-ET. Recommended for publication by Associate Editor A. Shapiro upon evaluation of reviewers' comments.

C. J. Hung and P. Lin are with the Department of Materials Science and Engineering, National Chiao Tung University, Hsinchu 300, Taiwan (e-mail: cjhung.mse97g@nctu.edu.tw; panglin@mail.nctu.edu.tw).

Y. H. Huang, C. H. Chen, and T. Y. Tseng are with the Department of Electronics Engineering and Institute of Electronics, National Chiao Tung University, Hsinchu 300, Taiwan (e-mail: kk916kk916@hotmail.com; enjoylife428@hotmail.com; tseng@cc.nctu.edu.tw).

Color versions of one or more of the figures in this paper are available online at http://ieeexplore.ieee.org.

Digital Object Identifier 10.1109/TCPMT.2014.2299554 allowing for the control of daylight, solar heat gain, and internal heat loss through the buildings windows [2]. Over the past few decades, tungsten trioxide $\left(\mathrm{WO}_{3}\right)$ has been regarded as the most promising inorganic EC material for its low cost, relatively easy synthesis, low power consumption, and high color contrast [3], [4].

It is well known that the color change in $\mathrm{WO}_{3}$ is directly related to the double injection/extraction of ions (i.e., $\mathrm{H}^{+}$, $\mathrm{Li}^{+}, \mathrm{K}^{+}, \mathrm{Na}^{+}$, etc) and electrons in the $\mathrm{WO}_{3}$ structure [5]. In particular, 1-D crystalline hexagonal $\mathrm{WO}_{3}$ (hex- $\mathrm{WO}_{3}$ ) showing the large tunnel structure has attracted recent extensive attention since its electrochemical insertion/extraction of ions into/from large tunnel structure is more easily exhibiting better EC properties than the other phases [6]. Thus, it is importance to prepare hex- $\mathrm{WO}_{3}$ with well-controlled shapes, sizes, and crystal structure for EC application.

Various 1-D hex- $\mathrm{WO}_{3}$ nanostructure growth methods, such as hydrothermal synthesis [7], [8], microwave-assisted hydrothermal method [9], solvothermal synthesis [10], vapor transport method [11], and template assisted growth method [12] have also been explored. However, hydrothermal synthesis is the most widely used method because other methods have their own characteristic drawbacks, including relatively expensive, high temperature, using single crystal substrate, under high vacuum conditions, and using dangerous reagents.

Thus, the hydrothermal synthesis was regarded as a facile, cost efficient, and universal synthetic method for preparing nanostructure with desirable compositional, morphological, and crystalline properties. Recently, much research has been focused on using the additive or capping agent and seed layer for the synthesis of 1-D hex- $\mathrm{WO}_{3}$ nanostructures [13], [19]; however, those methods may be relatively complex in the experimental procedure. There are currently great interests to develop a technique to directly grow of $1-\mathrm{D}$ hex- $\mathrm{WO}_{3}$ nanostructures on seed-free substrates without using additive or capping agent via hydrothermal method. But, it is still a great challenge.

In this paper, we report a facile and cost-efficient hydrothermal approach for direct growth of 3-D hex- $\mathrm{WO}_{3}$ nanowire (NW) networks on seed-free substrates without using additive or capping agent. Different morphologies and nanostructures can be obtained by varying the experimental parameters. In addition, the morphology evolution and the growth mech- 

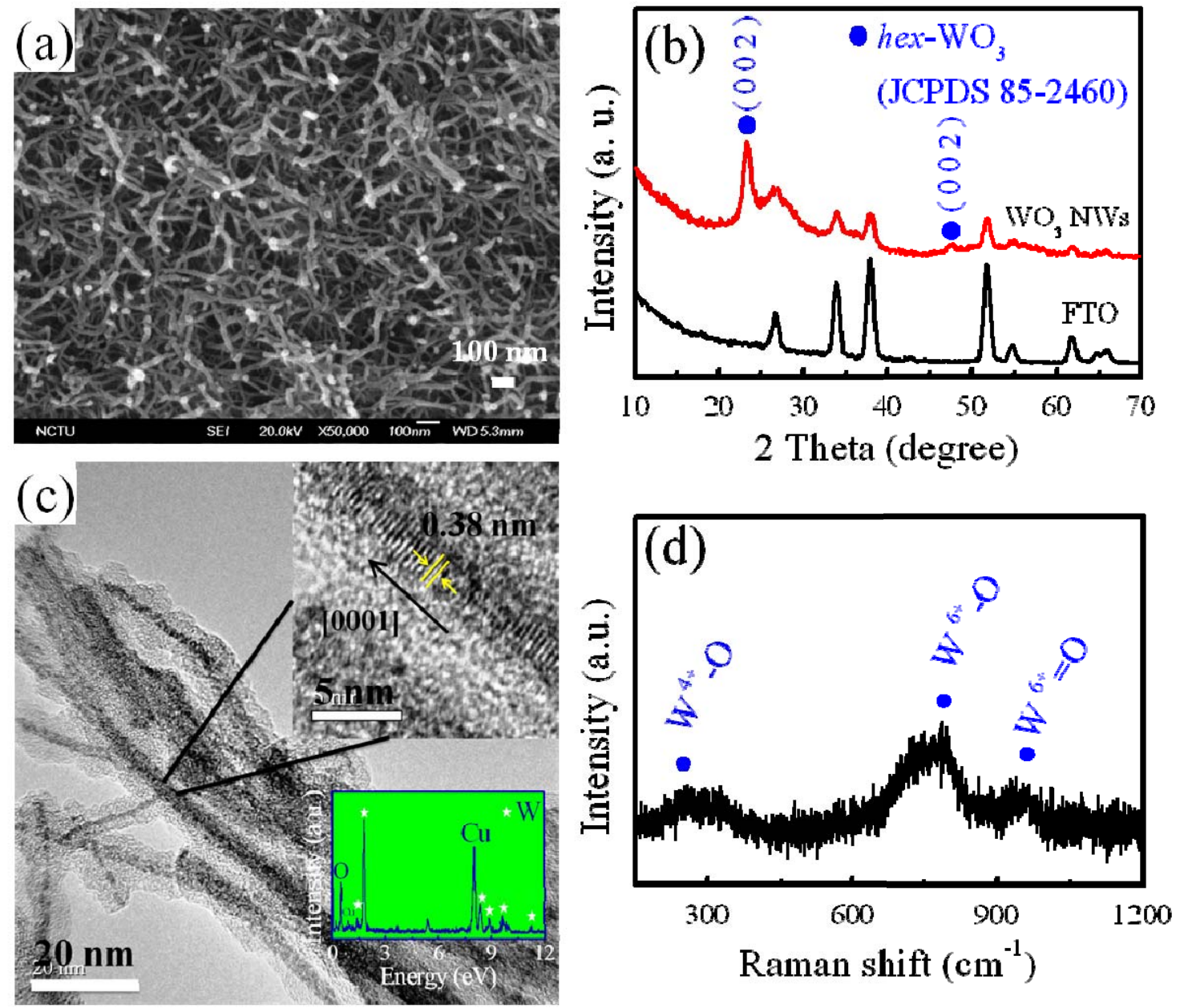

Fig. 1. (Color online) (a) SEM image. (b) XRD patterns. (c) TEM image (insets: HR-TEM image and EDX spectrum, respectively). (d) Raman spectra of the as-synthesized $\mathrm{WO}_{3} \mathrm{NWs}$.

anism are also reported. Finally, we successfully fabricate the high-performance EC device based on 3-D hex- $\mathrm{WO}_{3}$ NW networks.

\section{EXPERIMENT}

In this section, the optimal synthesis conditions for preparing $\mathrm{WO}_{3} \mathrm{NWs}$ on fluorine-doped tin oxide (FTO) glass substrate $(20 \mathrm{~mm} \times 30 \mathrm{~mm}$ in size $)$ utilizing the seed-layer free hydrothermal treatment are reported.

\section{A. Material Synthesis}

The precursor solution for hydrothermal treatment was prepared as follows. Tungsten hexachloride powder $\left(\mathrm{WCl}_{6}\right)$ was dissolved in isopropyl alcohol $\left(\mathrm{C}_{3} \mathrm{H}_{7} \mathrm{OH}\right)$ at $70{ }^{\circ} \mathrm{C}$ under vigorous stirring for $24 \mathrm{~h}$, giving a concentration of $40 \mathrm{mM}$, and then sodium hydroxide $(\mathrm{NaOH})$ was used to adjust the $\mathrm{pH}$ value to 2.0, resulting in the formation of a transparent and clear precursor solution. Subsequently, the as-prepared precursor solution was transferred to a teflon-sealed stainless steel autoclave. The FTO glass substrate (cleaned using ethanol, and deionized water, sequentially) is placed upside down in the above solution, and then the autoclave was sealed and maintained at $180{ }^{\circ} \mathrm{C}$ for $8 \mathrm{~h}$ for growing $\mathrm{WO}_{3} \mathrm{NWs}$. Once the hydrothermal reaction was finished, the autoclave was cooled down to room temperature naturally. At last, the as-deposited substrate, 3-D $\mathrm{WO}_{3}$ NWs networks on FTO glass, was washed by deionized water and dried at room temperature for further characterization.

To further understand the relation between the precursor solution $\mathrm{pH}$ value and the $\mathrm{WO}_{3} \mathrm{NWs}$ growth, the different precursor's $\mathrm{pH}$ values of $<1.0,1.0,3.0$, and 7.0 compared with 2.0 were carried out. In our experiments, the $\mathrm{pH}$ values of precursor solutions were adjusted by two steps. First, the initial $\mathrm{pH}$ value of the precursor solution was $<1.0$, then, it was adjusted to different final $\mathrm{pH}$ values by adding various amounts of $\mathrm{NaOH}$.

\section{B. Material Characterization}

The field emission scanning electron microscope (SEM, JEOL JSM-6700), high resolution transmission electron microscope (Cryo HR-TEM, JEOL JEM-2010), and X-ray diffractometer (XRD, Bede D1) were used to analyze surface morphology and crystallization of the $\mathrm{WO}_{3} \mathrm{NWs}$, respectively. Raman spectra of the as-synthesized $\mathrm{WO}_{3} \mathrm{NWs}$ were recorded 

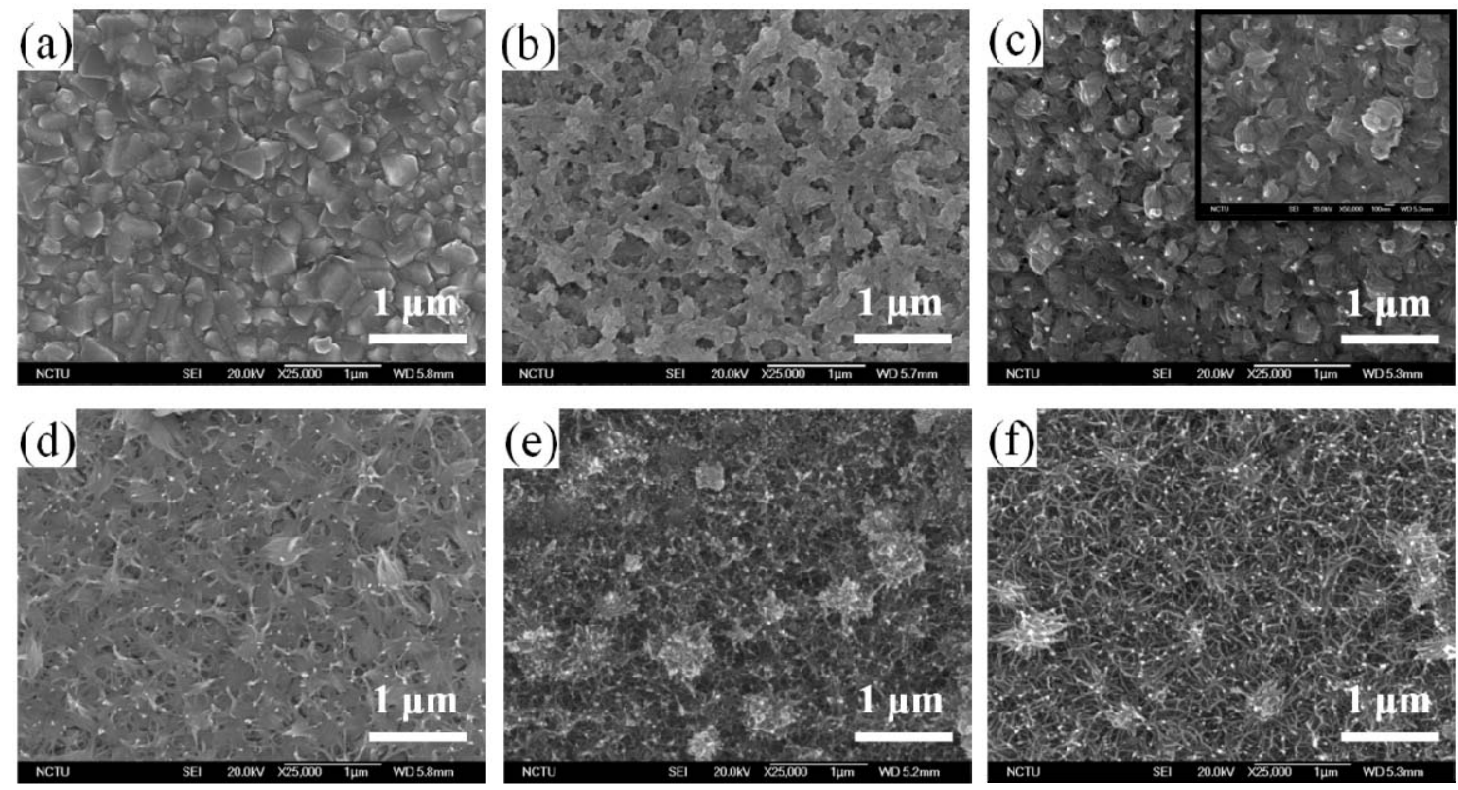

Fig. 2. SEM images of $\mathrm{WO}_{3}$ NWs grown at different reaction times. (a) Bare FTO. (b) 10 min. (c) 30 min (inset: high-magnification image). (d) 1 h. (e) $3 \mathrm{~h}$. (f) $12 \mathrm{~h}$.

using a HR confocal Raman microscope (HOROBA, Lab RAM HR). The laser excitation was provided by a regular model laser operating at $632.8 \mathrm{~nm}$.

The EC performances were measured between $\pm 1.0 \mathrm{~V}$ at a scan rate varied from 10 to $100 \mathrm{mV} \mathrm{s}^{-1}$ by cyclic voltammetry using $\mathrm{CH}$ Instruments 618B electrochemical analyzer. Electrochemical measurements were carried out in a threeelectrode cell based on the prepared $\mathrm{WO}_{3} \mathrm{NWs}$ on FTO glass as working electrode, a saturated calomel reference electrode as reference electrode, platinum sheet as counter electrode, and $1 \mathrm{M} \mathrm{LiClO} /$ propylene carbonate (PC) as electrolyte. The coloration/bleaching switching behavior of $\mathrm{WO}_{3} \mathrm{NWs}$ on FTO glass were measured by in situ optical measurement using an UV-vis spectrophotometer (Hitachi U-3010) at a wavelength of $632 \mathrm{~nm}$ with alternately applying a square wave voltage of $\pm 2.0 \mathrm{~V}, 100 \mathrm{~s}$ for each state.

Finally, an EC device $(50 \mathrm{~mm} \times 50 \mathrm{~mm})$ was successfully fabricated with a simple two-electrode configuration. Here, $\mathrm{WO}_{3}$ NWs on FTO glass as working electrode and another bare FTO glass as counter electrode were sandwiched together with epoxy. Then, a mixture of polyvinylidene fluoride/lithium perchlorate $\left(\mathrm{LiClO}_{4}\right) / 1$-methyl-2-pyrrolidone/diethyl carbonate/PC (5:11:70:7:7 wt\%) as the gel electrolyte was injected into the space between two electrodes, until all air was replaced.

\section{RESUlTS AND Discussion}

The morphology and microstructural properties of as-synthesized $\mathrm{WO}_{3}$ NWs were investigated. Fig. 1(a) shows the typical top-view SEM surface morphology of the $\mathrm{WO}_{3} \mathrm{NWs}$, synthesized via a hydrothermal method at $180{ }^{\circ} \mathrm{C}$ for $8 \mathrm{~h}$ when the $\mathrm{pH}$ value of the precursor is fixed at 2.0. It is indicated that a random, porous, interwoven continuous network of NWs deposited onto FTO glass substrate. Each NW has a uniform diameter of $8 \mathrm{~nm}$ and length ranging from one to several tens of nanometers. It was suggested that $\mathrm{WO}_{3}$ with high porosity and structural continuity can achieve fast and sufficient intercalation of ions improving its coloration efficiency (CE) and switching time [20].

Fig. 1(b) shows XRD patterns of the bare FTO substrate and $\mathrm{WO}_{3}$ NWs. After subtracting the diffraction peaks of FTO substrate, two main peaks at $2 \theta$ around $23.3^{\circ}(002)$ and $47.8^{\circ}$ (004) are observed for $\mathrm{WO}_{3}$ NWs. It is clearly confirmed that the as-synthesized $\mathrm{WO}_{3} \mathrm{NWs}$ has a hexagonal phase with unit cell parameters of $a=b=7.324 \AA$ and $c=7.662 \AA$ (JCPDS \# 85-2460). The sharp diffraction peaks indicate good crystallinity of the as-synthesized products. In addition, the strong (002) peak and weak (004) peak suggest that the $\mathrm{WO}_{3}$ NWs grow toward [001] direction and align with their $c$-axis oriented growth. It was reported that the faster EC response was due to the $\mathrm{WO}_{3}$-based $\mathrm{EC}$ film in a hexagonal structure with large tunnels [21].

Fig. 1(c) shows the plane view TEM image of the assynthesized $\mathrm{WO}_{3} \mathrm{NWs}$. It indicates that the obtained NWs have a typical diameter of $\sim 8 \mathrm{~nm}$. The surface morphologies of the NWs are very rough, which increase their surface areas. In addition, the HR-TEM image shown in the inset of Fig. 1(c) shows the lattice $d$-spacing of $0.38 \mathrm{~nm}$, which correspond to the (002) crystalline plane of hex- $\mathrm{WO}_{3}$, confirming that the $\mathrm{NW}$ is $c$-axis oriented. This result is consistent with XRD and SEM results.

Raman spectroscopy was used to investigate the vibrational properties of as-synthesized $\mathrm{WO}_{3} \mathrm{NWs}$, as shown in Fig. 1(d). It indicates that there are three main spectral regions in the Raman spectra. The highest frequency $\sim 950 \mathrm{~cm}^{-1}$ shows the $\mathrm{W}^{6+}=\mathrm{O}$ stretch from hydrates or cluster boundaries [22]; the second highest frequency from 600 to $800 \mathrm{~cm}^{-1}$ relates the $\mathrm{W}^{6+}-\mathrm{O}$ single bonds of the bridging oxygen atoms of $\left(\mathrm{WO}_{6}\right)$ octahedral units [23], and the low frequency region 

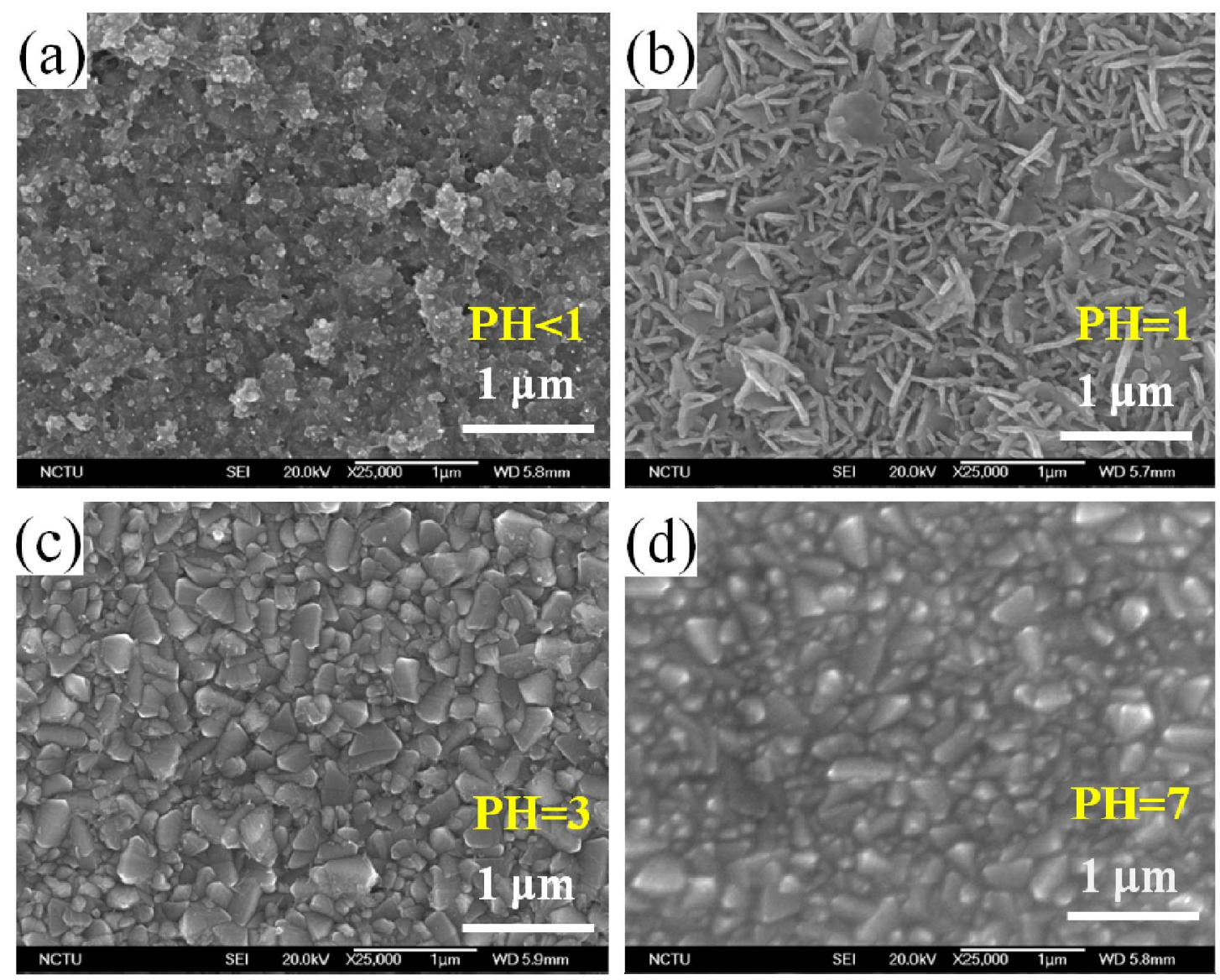

Fig. 3. SEM images of $\mathrm{WO}_{3}$ NWs obtained at various pH values. (a) <1.0. (b) 1.0. (c) 3.0. (d) 7.0.

$\sim 200-400 \mathrm{~cm}^{-1}$ correlates to $\mathrm{W}^{4+}{ }_{-} \mathrm{O}$ and $\mathrm{W}^{5+}{ }_{-} \mathrm{O}$ vibrations [24], respectively. According to [25] and [26], these results revealed that the as-synthesized products were pure $\mathrm{WO}_{3} \mathrm{NWs}$ with a hexagonal phase and no hydrated $\mathrm{WO}_{3}$ was found. Raman result is also consistent with the results of XRD and TEM analyzes.

In order to further understand the formation process of $\mathrm{WO}_{3}$ nanostructure, identical starting solutions for the preparation of NWs were hydrothermally treated for different reaction times and their morphologies are shown in Fig. 2. Reaction times were $10 \mathrm{~min}, 30 \mathrm{~min}, 1 \mathrm{~h}, 3 \mathrm{~h}, 8 \mathrm{~h}$, and $12 \mathrm{~h}$, respectively. The morphology of the bare FTO substrate surface without precoating is shown in Fig. 2(a). When the system is reacted for $10 \mathrm{~min}$, the amount of large irregular particles is formed [Fig. 2(b)]. After $30 \mathrm{~min}$ of reaction, the products exhibit bundle-like and irregular shapes, as shown in Fig. 2(c). From the high magnification image [inset of Fig. 2(c)], the bundlelike structure is constructed from the assembly of smaller nanorods.

At a reaction time of $1 \mathrm{~h}$, the bundle-like aggregates transform into NWs and as-grown NWs are not uniform in size and shape and some irregular particles appear in the products, as shown in Fig. 2(d). With increasing growth time to $3 \mathrm{~h}$, NWs are scattered randomly on the substrate, and some spherical aggregates NWs can be observed in Fig. 2(e). When the reaction time prolonged to $8 \mathrm{~h}$, the spherical aggregates eventually disappeared and keep on growing to the final NWs, as shown in Fig. 1(a). Finally, the morphology of the NWs is not significantly changed when prolonging the reaction time to $12 \mathrm{~h}$, as shown in Fig. 2(f). It is worth pointing out that the $\mathrm{pH}$ increases rapidly within the first $1 \mathrm{~h}$, then reaches to a constant level of $\sim 3.0$ until the reaction finished.

Based on the results described above, we can easily predict the possible formation mechanism based on the NWs microstructural evolution through the variation of hydrothermal reaction time. During the hydrothermal synthesis of $\mathrm{WO}_{3}$ NWs, the chemical reactions occurred in the preparing process are as follows:

$$
\begin{array}{r}
\mathrm{WCl}_{6}+6 \mathrm{C}_{3} \mathrm{H}_{7} \mathrm{OH} \rightarrow \mathrm{W}\left(\mathrm{OC}_{3} \mathrm{H}_{7}\right)_{6}+6 \mathrm{HCl} \\
\mathrm{W}\left(\mathrm{OC}_{3} \mathrm{H}_{7}\right)_{6 \text { (ion) }} \stackrel{\text { hydrothermalprocess }}{\longrightarrow} \mathrm{WO}_{3(\mathrm{~s})}+6\left(\mathrm{C}_{3} \mathrm{H}_{6}\right) \\
+3 \mathrm{H}^{+}+3 \mathrm{OH}^{-} \\
\mathrm{WO}_{3(\mathrm{~s})}+\mathrm{OH}^{-} \rightarrow \mathrm{WO}_{4(\text { ion })}^{2-}+\mathrm{H}^{+}(\mathrm{pH}>2)
\end{array}
$$

At the initial reaction stage, two chemical reactions [(1) and (2)] occurred in the precursor solutions. When the temperature exceeded the decomposition temperature of $\mathrm{W}(\mathrm{OC} 3 \mathrm{H} 7)_{6}$, nucleation started and the $\mathrm{WO}_{3}$ crystal nuclei were quickly formed and aggregated irregular particles on the FTO substrate. It is well known that the nucleation rate is determined by the exponential decay [27]. Hence, it undergoes 

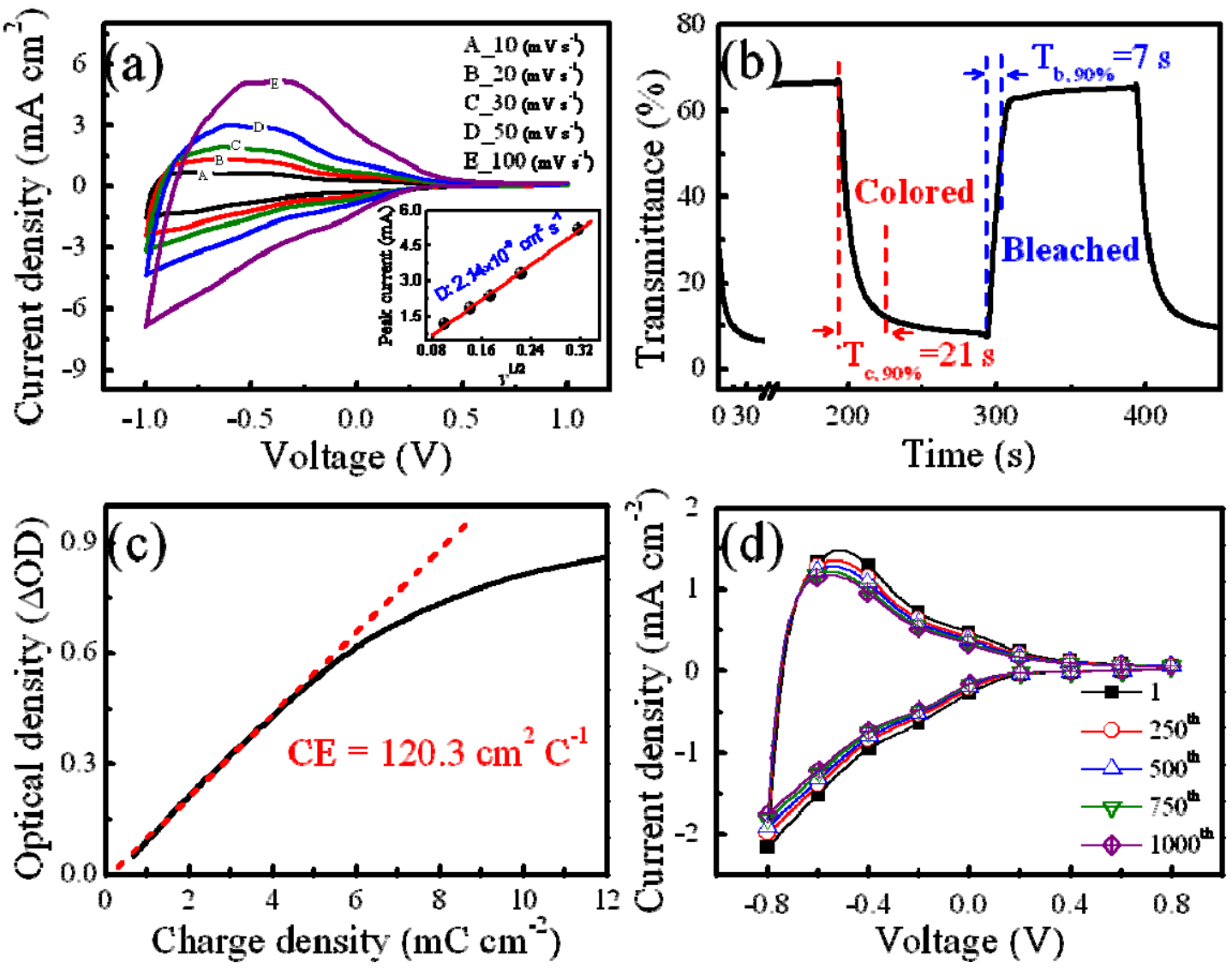

Fig. 4. (Color online) (a) $C-V$ curves of the as-synthesized WO3 NWs film recorded at $10,20,30,50$, and $100 \mathrm{mV} \mathrm{s}^{-1}$, respectively. Inset: peak current density as a function of the square root of the scan rates. (b) Transmittance variation and switching time characteristics between the colored and bleached states measured at $\pm 2.0 \mathrm{~V}$ for $100 \mathrm{~s}$ with a wavelength of $632 \mathrm{~nm}$. (c) Variation of the $\Delta \mathrm{OD}$ with the charge density (measured at $632 \mathrm{~nm}$, $-2.0 \mathrm{~V}$ bias). (d) $C-V$ curves of the as-synthesized $\mathrm{WO}_{3} \mathrm{NWs}$ film for the 1000 cycles and measured in $1 \mathrm{M} \mathrm{LiClO}_{4} / \mathrm{PC}_{\mathrm{s}}$ solution with a sweep rate of $50 \mathrm{mV} \mathrm{s}^{-1}$.

a rapid nucleation within the first $1 \mathrm{~h}$ and then nucleation rate slows down with increasing reaction time in our experiment.

Meanwhile, some $\mathrm{WO}_{3}$ nuclei could be dissolved in aqueous-like alkaline solutions to form tungstate ions, $\mathrm{WO}_{4}^{2-}$, following (3) [28]. During the synthetic process, it is expected that the dissolution rate increases rapidly within the first $1 \mathrm{~h}$ due to rapid increase of $\mathrm{pH}$ and then it remains at constant until the reaction is finished. However, tungstate ions $\left(\mathrm{WO}_{4}^{2-}\right)$ in solution reach the saturation level after hydrothermal treated at $180{ }^{\circ} \mathrm{C}$ for $6 \mathrm{~h}$, and then the dissolution rate will drop slowly below critical level in a closed system until the reaction is finished.

As described above, hydrothermal growth of $\mathrm{WO}_{3} \mathrm{NWs}$ can be divided into three periods in our experiment. In region 1 , where nucleation rate is much faster than dissolution rate, $\mathrm{WO}_{3}$ nuclei are rapidly formed from the precursors, which further aggregates and formed by irregular nanoparticles [Fig. 2(b)].

In region 2 , where nucleation rate is less than dissolution rate, it can be seen that the bundle-like NWs gradually begin to appear, which are attributed to lateral dissolution processes [Fig. 2(c)]. With increasing the hydrothermal time, those bundle-like NWs begin to split with each other to form NWs networks, and become thinner due to the continuous lateral dissolution process [Fig. 2(d)]. In the meantime, the nucleation and crystallization of NWs are still in progress in a longitudinal direction. So, longer NWs could be synthesized on increasing reaction time [Fig. 2(e)].

In region 3 , where the nucleation rate is slightly faster than dissolution rate, well-dispersed NWs are obtained leading to a highly porous NW network structure [Fig. 1(a)]. On the other hand, the small $\mathrm{WO}_{3}$ nanoparticles can also be precipitated directly on the surface of as-grown NWs with further increasing reaction time, which causes destruction of NWs networks [Fig. 2(f)].

Influence of the precursor solution $\mathrm{pH}$ value on growth of $\mathrm{WO}_{3}$ nanostructure was also intensively investigated. Fig. 3 shows the typical SEM images of the as-synthesized $\mathrm{WO}_{3}$ products with different morphologies at various $\mathrm{pH}$ values. When the growth is conducted at a low $\mathrm{pH}$ value $(<1.0)$, SEM result is shown in Fig. 3(a), some irregular particles are formed. Increasing the $\mathrm{pH}$ to 1.0 , plate-like nanostructure is grown, as shown in Fig. 3(b). Fig. 1(a) shows large scale uniform NWs nanostructure is deposited by controlling $\mathrm{pH}$ value of 2.0. Finally, as the $\mathrm{pH}$ values are controlled from 3.0 to 7.0 and keeping other experimental parameters constant, no precipitates are obtained [Fig. 3(c) and (d)]. These results are consistent with previous report [16]. On the basis of 
(a)
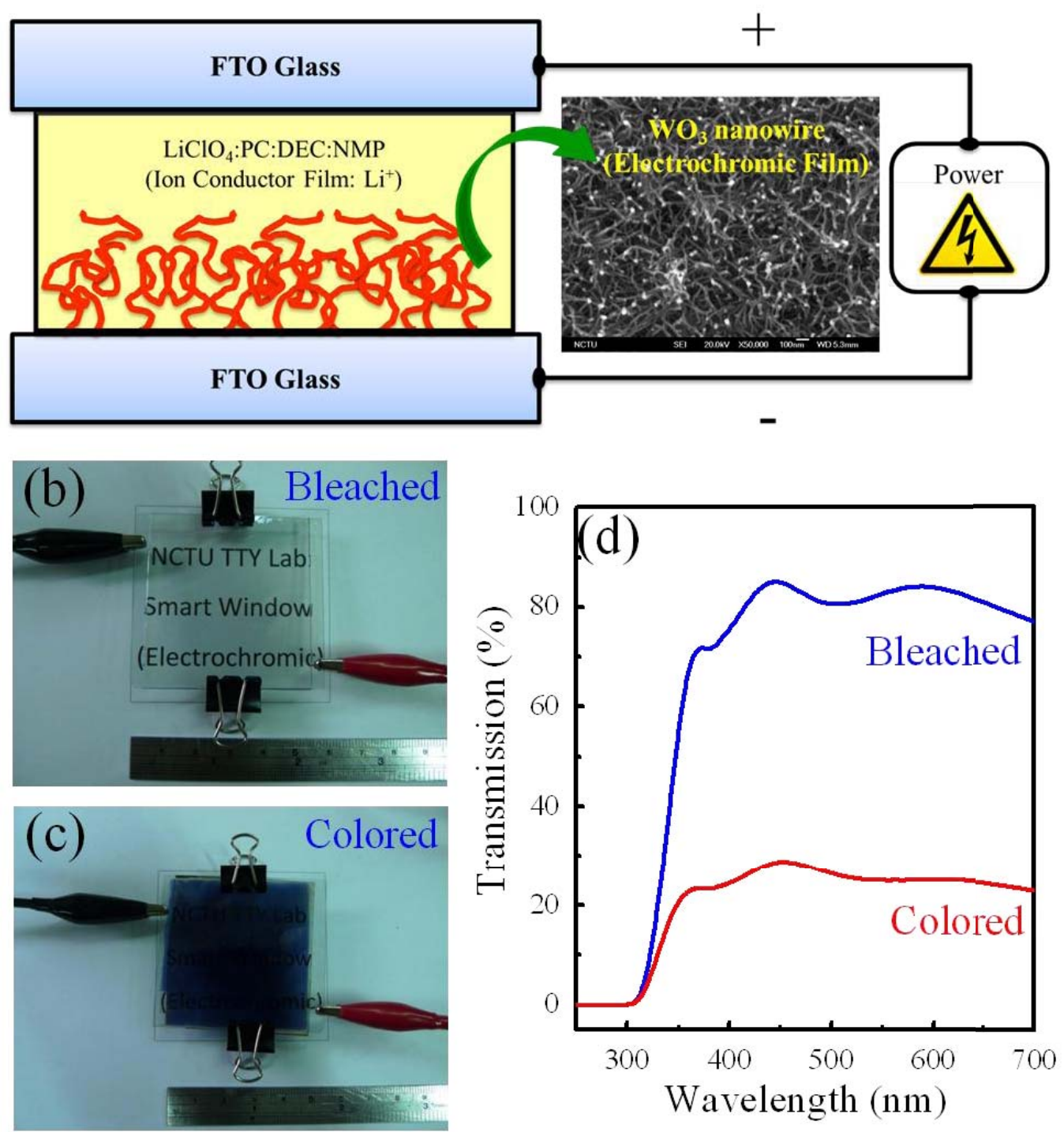

Fig. 5. (a) Schematic diagram of an EC device $(50 \mathrm{~mm} \times 50 \mathrm{~mm})$ operating at biases of $\pm 2.0 \mathrm{~V}$. (b) and (c) Photos of the bleached/colored EC devices after applying potentials. (d) Optical transmittance spectra for the EC device in the colored and bleached states.

microscopic results, we conclude that the $\mathrm{pH}$ value of the precursor solution has a strong influence on the morphology and crystal structure of the final products. The EC behaviors of the as-synthesized 3-D hex- $\mathrm{WO}_{3}$ NWs networks on FTO-coated glass as a working electrode were evaluated on the test cell of a traditional three-electrode electrochemical workstation. Fig. 4(a) shows the $C-V$ curves measured at various scan rates of $10,20,30,50$, and $100 \mathrm{mV} \mathrm{s}^{-1}$ from $-1.0 \mathrm{~V}$ (coloration) to $1.0 \mathrm{~V}$ (bleaching). All the $C-V$ curves appear almost a typical curve shape and welldefined anodic peak, which is in agreement with previous reports of proton insertion in $\mathrm{WO}_{3}$ [29]. In addition, it is also observed that when the scan rates increased, the anodic current peak slightly shifted toward more positive potentials (from -0.84 to $-0.42 \mathrm{~V}$ ). The above result indicates a limitation in the charge-transfer kinetics [30]. It is regarded that a charge-transfer resistance occurred due to slow activation reaction rates on electron and $\mathrm{Li}^{+}$between electrode and electrolyte, and transport limitation is a resistance caused by retarded diffusion [31].

To further understand the relationship between the mobility of ions and electrons, the dependence between current peak and scan rate is plotted in the inset of Fig. 4(a). It indicates that the peak current density $i_{p}$ exhibits a good linear relationship with the square root of scan rate $v^{1 / 2}$, which illustrates a surface-confined redox process [32]. In addition, the $\mathrm{Li}^{+}$diffusion coefficient can be calculated from a linear relationship between $i_{p}$ and $v^{1 / 2}$ according to the following Randles-Sevcik's equation:

$$
i_{p}=\left(2.69 \times 10^{5}\right) n^{3 / 2} \mathrm{ACD}^{1 / 2} v^{1 / 2}
$$

where $n$ is stoichiometric number of electrons involved in the reaction, $A$ is the area of the electrode $\left(\mathrm{cm}^{2}\right), C$ is the $\mathrm{Li}^{+}$ concentration of the diffusion component $\left(\mathrm{mol} \mathrm{cm}^{-3}\right), D$ is the diffusion coefficient of $\mathrm{Li}^{+}\left(\mathrm{cm}^{2} \mathrm{~s}^{-1}\right)$, and $v$ is the scan rate of the applied potential $\left(\mathrm{V} \mathrm{s}^{-1}\right)$. For an area of $2 \mathrm{~cm}^{2}$ 
and $C=1 \mathrm{M}$, the diffusion coefficient of the $\mathrm{Li}^{+}$in the 3-D hex- $\mathrm{WO}_{3}$ NWs networks-based EC film with $\mathrm{LiClO}_{4}+\mathrm{PC}$ electrolyte is calculated to be $2.14 \times 10^{-9} \mathrm{~cm}^{2} \mathrm{~s}^{-1}$, even better than the reported results [5], [33], [34]. It reveals that fast ions transport can quickly and easily diffused into redox-active species on the surface of each NWs. It is well established that the 3-D hex- $\mathrm{WO}_{3} \mathrm{NWs}$ networks-based EC film exhibits excellent electrochemical behavior.

To evaluate the coloration; bleaching kinetic of the electrode, in situ transmittance change is measured at a wavelength of $632 \mathrm{~nm}$ with alternately applying potential of $\pm 2.0 \mathrm{~V}$ for $100 \mathrm{~s}$, as shown in Fig. 4(b). The coloration and bleaching times are defined as the time required for a $90 \%$ change in the full transmittance modulation at specified wavelength. The coloration time of $90 \%$ changes $T_{c}, 90 \%$ is found to be $21 \mathrm{~s}$ while bleaching time $T_{b}, 90 \%$ is $7 \mathrm{~s}$. The coloration/bleaching times are better than those reported in the other similar studies [5], [7], [34], [35]. The characteristics of 3-D hex- $\mathrm{WO}_{3} \mathrm{NWs}$ networks make them suitable for making EC devices. Fast switching responses are attributed to the high surface area, large hexagonal tunnels, and good interconnection network of the $\mathrm{WO}_{3} \mathrm{NWs}$. This result implies that $\mathrm{Li}^{+}$can quickly and easily inserting/extracting and migrates in large tunnels. In fact, the switching response is highly dependent on the diffusion coefficient of $\mathrm{Li}^{+}$and a high diffusion coefficient also exhibits a faster response.

Another important consideration is the $\mathrm{CE}$, which is defined as the change in optical density $(\Delta \mathrm{OD})$ per unit of charge $(\Delta Q)$ intercalated into the EC porous film. One of the important parameters often used to evaluate EC performance [40]. It can be calculated from the following equations:

$$
\begin{aligned}
\mathrm{CE} & =\frac{\Delta \mathrm{OD}}{\Delta Q} \\
\Delta \mathrm{OD} & =\log \left(\frac{T_{b}}{T_{c}}\right)
\end{aligned}
$$

where $T_{b}$ and $T_{c}$ are the bleached and colored transmittance values, respectively. Fig. 4(c) shows the plot of $\Delta \mathrm{OD}$ versus inserted charge density at a coloration potential of $\pm 2.0 \mathrm{~V}$ and at a wavelength of $632 \mathrm{~nm}$. The $\mathrm{CE}$ value is extracted from the slope of the line fitted to the linear region of the curve. As a result, the calculated CE value of EC film is $120.3 \mathrm{~cm}^{2} \mathrm{C}^{-1}$, which is better than those reported work [5], [18], [34], [36], [38]. The higher CE value indicates that 3-D hex- $\mathrm{WO}_{3} \mathrm{NW}$ networks with a very high specific surface area provide good ion access with a high electrical conductivity. An excellent EC material should maximize its $\mathrm{CE}$, corresponding to a large transmittance change induced by a small amount of charge [39].

Furthermore, the long-term cycling durability of the EC porous film is also investigated. $C-V$ curves after a few initial cycles of stabilization and optimization are recorded every 250 cycles at room temperature and the result is shown in Fig. 4(d). Test is performed at a $50 \mathrm{mV} \mathrm{s}^{-1}$ sweep speed between $\pm 0.8 \mathrm{~V}$. It is shown that there is no obvious change in the current densities after 1000 cycles, only a slight reduction ( $\sim 87 \%$ of the initial value) appears indicating excellent cycling durability of the $3-\mathrm{D}$ hex- $\mathrm{WO}_{3} \mathrm{NWs}$ networks-based EC film.

Finally, we fabricated an EC device $(50 \mathrm{~mm} \times 50 \mathrm{~mm})$ with a simple two-electrode configuration as preliminary investigation, as shown in Fig. 5(a). The 3-D hex- $\mathrm{WO}_{3} \mathrm{NWs}$ networks were coated onto FTO glass as one electrode. Then, the designed gel electrolyte was spread on the bare FTO glass as a counter electrode and two electrodes were sandwiched. To prevent leakage, an epoxy resin was applied to seal the device. Such EC device operating at biases of $\pm 2.0 \mathrm{~V}$ reveals a good contrast between the bleached [Fig. 5(b)] and colored [Fig. 5(c)] states, which leads to the obvious transparence changes [Fig. 5(d)]. We believe that the device shows promising applications in energy saving with smart windows.

\section{CONCLUSION}

In summary, 3-D hex- $\mathrm{WO}_{3}$ NWs network film was successfully coated on seed-free FTO substrates without using additive or capping agent by using a facile and cost-efficient hydrothermal approach. It is shown that the hydrothermal reaction time and $\mathrm{pH}$ of the precursor solutions both have a significant influence on the orientation and morphology of as-prepared $\mathrm{WO}_{3}$ products. The XRD, HR-TEM, SEM, and Raman spectroscopy investigations all evidenced the good hexagonal structure, crystallinity, and highly porous structure with large surface area of the NWs film. It reveals that fast ions transport can quickly and easily diffused into the storage sites of the porous film. The 3-D hex- $\mathrm{WO}_{3} \mathrm{NW}$ networks have a high $\mathrm{Li}^{+}$diffusion coefficient $2.14 \times 10^{-9} \mathrm{~cm}^{2} \mathrm{~s}^{-1}$, which results in having a significant optical modulation (57\% at $632 \mathrm{~nm}$ ), fast EC response time (coloring time $\sim 21 \mathrm{~s}$, bleaching time $\sim 7 \mathrm{~s}$ ), and outstanding high coloration efficiency $\sim 120.3 \mathrm{~cm}^{2} \mathrm{C}^{-1}$. Besides, the EC device exhibits high stability, which is $\sim 87 \%$ of the initial current density after 1000 cycles, indicating the excellent cycle durability. Furthermore, an EC device $(50 \mathrm{~mm} \times 50 \mathrm{~mm})$ with a simple two-electrode configuration was successfully fabricated using an epoxy resin to seal the device, which shows high optical contrast after operating at $\pm 2.0 \mathrm{~V}$ biases. Our designed $3-\mathrm{D}$ hex- $\mathrm{WO}_{3} \mathrm{NW}$ network film using a facile hydrothermal method exhibits large optical modulations, fast switching times, and long cyclic stabilities, suitable for large-area smart window application.

\section{REFERENCES}

[1] D. T. Gillaspie, R. C. Tenent, and A. C. Dillon, "Metal-oxide films for electrochromic applications: Present technology and future directions," J. Mater. Chem., vol. 20, pp. 9585-9592, Aug. 2010.

[2] S. M. Wang, L. Liu, W. L. Chen, Z. M. Zhang, Z. M. Su, and E. B. Wang, "A new electrodeposition approach for preparing polyoxometalatesbased electrochromic smart windows," J. Mater. Chem. A, vol. 1, pp. 216-220, Nov. 2013.

[3] M. C. Rao, "Structure and properties of $\mathrm{WO}_{3}$ thin films for electrochromic device application," J. Non-Oxide Glass, vol. 5, no. 1, pp. 1-8, 2013

[4] Z. Yao, J. Di, Z. Yong, Z. Zhao, and Q. Li, "Aligned coaxial tungsten oxide-carbon nanotube sheet: A flexible and gradient electrochromic film," Chem. Commun., vol. 48, no. 66, pp. 8252-8254, 2012.

[5] S. S. Kalagi, S. S. Mali, D. S. Dalavi, A. I. Inamdar, H. Im, and P. S. Patil, "Transmission attenuation and chromic contrast characterization of R.F. sputtered $\mathrm{WO}_{3}$ thin films for electrochromic device applications," Electrochim. Acta, vol. 85, pp. 501-508, Dec. 2012. 
[6] L. Chen, S. Lam, Q. Zeng, R. Amal, and A. Yu, "Effect of cation intercalation on the growth of hexagonal $\mathrm{WO}_{3}$ nanorods," J. Phys. Chem. $C$, vol. 116, no. 21 , pp. 11722-11727, 2012.

[7] J. Wang, E. Khoo, P. S. Lee, and J. Ma, "Synthesis, assembly, and electrochromic properties of uniform crystalline $\mathrm{WO}_{3}$ nanorods," J. Phys. Chem. C, vol. 112, no. 37, pp. 14306-14312, 2008.

[8] K. O. Iwu, A. Galeckas, P. Rauwel, A. Y. Kuznetsov, and T. Norby, "One-dimensional $\mathrm{WO}_{3}$ and its hydrate: One-step synthesis, structural and spectroscopic characterization," J. Solid State Chem., vol. 185, pp. 245-252, Jan. 2012

[9] A. Phuruangrat, D. J. Ham, S. J. Hong, S. Thongtem, and J. S. Lee, "Synthesis of hexagonal $\mathrm{WO}_{3}$ nanowires by microwave-assisted hydrothermal method and their electrocatalytic activities for hydrogen evolution reaction," J. Mater. Chem., vol. 20, no. 1, pp. 1683-1690, 2010.

[10] H. G. Choi, Y. H. Jung, and D. K. Kim, "Solvothermal synthesis of tungsten oxide nanorod/nanowire/nanosheet," J. Amer. Ceram. Soc., vol. 88, no. 6, pp. 1684-1686, 2005.

[11] D. Meng, N. M. Shaalan, T. Yamazaki, and T. Kikuta, "Preparation of tungsten oxide nanowires and their application to $\mathrm{NO}_{2}$ sensing," Sens. Actuator B, Chem., vol. 169, pp. 113-120, Jul. 2012.

[12] K. Zhu, H. He, S. Xie, X. Zhang, W. Zhou, S. Jin, et al., "Crystalline $\mathrm{WO}_{3}$ nanowires synthesized by templating method," Chem. Phys. Lett., vol. 377, pp. 317-321, Aug. 2003.

[13] J. H. Ha, P. Muralidharan, and D. K. Kim, "Hydrothermal synthesis and characterization of self-assembled $\mathrm{h}-\mathrm{WO}_{3}$ nanowires/nanorods using EDTA salts," J. Alloys Compounds, vol. 475, pp. 446-451, May 2009.

[14] Y. H. Jun, C. Y. Qi, Y. Fang, P. Y. Hua, H. X. Wu, Z. Ding, et al., "Hydrothermal synthesis and chromic properties of hexagonal $\mathrm{WO}_{3}$ nanowires," Chin. Phys. B, vol. 20, no. 3, pp. 036103-1-036103-6, 2011.

[15] S. Bai, K. Zhang, R. Luo, D. Li, A. Chen, and C. C. Liu, "Lowtemperature hydrothermal synthesis of $\mathrm{WO}_{3}$ nanorods and their sensing properties for $\mathrm{NO}_{2}$, J J. Mater. Chem., vol. 22, no. 1, pp. 12643-12650, 2012.

[16] K. Huang, Q. Pan, F. Yang, S. Ni, X. Wei, and D. He, "Controllable synthesis of hexagonal $\mathrm{WO}_{3}$ nanostructures and their application in lithium batteries," J. Phys. D, Appl. Phys., vol. 1, no. 15, pp. 155417-1-155417-6, 2008.

[17] F. Zheng, H. Lu, M. Guo, and M. Zhang, "Effect of substrate pretreatment on controllable synthesis of hexagonal $\mathrm{WO}_{3}$ nanorod arrays and their electrochromic properties," CrystEngComm, vol. 15, no. 29, pp. 5828-5837, 2013.

[18] J. Zhang, J. P. Tu, X. H. Xia, X. L. Wang, and C. D. Gu, "Hydrothermally synthesized $\mathrm{WO}_{3}$ nanowire arrays with highly improved electrochromic performance," J. Mater. Chem., vol. 21, no. 1, pp. 5492-5498, 2011.

[19] K. Huang, Q. Zhang, F. Yang, and D. He, "Ultraviolet photoconductance of a single hexagonal $\mathrm{WO}_{3}$ nanowire," Nano Res., vol. 3, no. 4, pp. 281-287, 2010.

[20] J. Z. Ou, S. Balendhran, M. R. Field, D. G. McCulloch, A. S. Zoolfakar, R. A. Rani, et al., "The anodized crystalline $\mathrm{WO}_{3}$ nanoporous network with enhanced electrochromic properties," Nanoscale, vol. 4, no. 19, pp. 5980-5988, 2012.

[21] H. Zheng, J. Z. Ou, M. S. Strano, R. B. Kaner, A. Mitchell, and K. Kalantar-zadeh, "Nanostructured tungsten oxide-Properties, synthesis, and applications," Adv. Funct. Mater., vol. 21, no. 12, pp. 2175-2196, 2011.

[22] B. Moshofsky and T. Mokari, "Length and diameter control of ultrathin nanowires of substoichiometric tungsten oxide with insights into the growth mechanism," Chem. Mater, vol. 25, no. 8, pp. 1384-1391, 2013.

[23] S. H. Lee, H. M. Cheong, C. E. Tracy, A. Mascarenhas, D. K. Benson, and S. K. Deb, "Raman spectroscopic studies of electrochromic a- $\mathrm{WO}_{3}$," Electrochim. Acta, vol. 44, no. 18, pp. 3111-3115, 1999.

[24] C. S. Blackman and I. P. Parkin, "Atmospheric pressure chemical vapor deposition of crystalline monoclinic $\mathrm{WO}_{3}$ and $\mathrm{WO}_{3-x}$ thin films from reaction of $\mathrm{WCl}_{6}$ with O-containing solvents and their photochromic and electrochromic properties," Chem. Mater., vol. 17, no. 6, pp. 1583-1590, 2005.

[25] J. Li, X. Liu, Q. Han, X. Yao, and X. Wang, "Formation of $\mathrm{WO}_{3}$ nanotube-based bundles directed by $\mathrm{NaHSO}_{4}$ and its application in water treatment," J. Mater. Chem. A, vol. 1, no. 4, pp. 1246-1253, 2013.

[26] A. Sonia, Y. Djaoued, B. Subramanian, R. Jacques, M. Eric, B. Ralf, et al., "Synthesis and characterization of novel nanorod superstructures and twin octahedral morphologies of $\mathrm{WO}_{3}$ by hydrothermal treatment," Mater. Chem. Phys., vol. 136, no. 1, pp. 80-89, 2012.
[27] Z. Cao and F. A. Ferrone, "Homogeneous nucleation in sickle hemoglobin: Stochastic measurements with a parallel method," Biophys. J., vol. 72, no. 1, pp. 343-352, 1997.

[28] C. L. Rollinson, The Chemistry of Chromium, Molybdenum and Tungsten, vol. 21. New York, NY, USA: Pergamon, 1975.

[29] H. Zhang, G. Duan, G. Liu, Y. Li, X. Xu, Z. Dai, et al., "Layer-controlled synthesis of $\mathrm{WO}_{3}$ ordered nanoporous films for optimum electrochromic application," Nanoscale, vol. 5, no. 6, pp. 2460-2468, 2013.

[30] L. W. Zhi, L. Y. Qin, and H. G. Qi, "Preparation of manganese dioxide modified glassy carbon electrode by a novel film plating/cyclic voltammetry method for $\mathrm{H}_{2} \mathrm{O}_{2}$ detection," J. Chilean Chem. Soc. vol. 54, no. 4, pp. 366-371, 2009.

[31] Z. He, N. Wagner, S. D. Minteer, and L. T. Angenent, "An upflow microbial fuel cell with an interior cathode: Assessment of the internal resistance by impedance spectroscopy," Environ. Sci. Technol., vol. 40, no. 17, pp. 5212-5217, 2006.

[32] W. M. Costa, W. S. Cardoso, E. P. Marques, C. W. B. Bezerra, A. A. P. Ferreira, C. Song, et al., "Electrochemical behavior of ruthenium-hexacyanoferrate modified glassy carbon electrode and catalytic activity towards ethanol electrooxidation," J. Brazilian Chem. Soc., vol. 24, no. 4, pp. 651-656, 2013.

[33] L. Liang, J. Zhang, Y. Zhou, J. Xie, X. Zhang, M. Guan, et al., "High-performance flexible electrochromic device based on facile semiconductor-to-metal transition realized by $\mathrm{WO}_{3} .2 \mathrm{H}_{2} \mathrm{O}$ ultrathin nanosheets," Sci. Rep., vol. 3, pp. 1936-1-1936-8, Jun. 2013.

[34] Z. Jiao, X. W. Sun, J. Wang, L. Ke, and H. V. Demir, "Hydrothermally grown nanostructured $\mathrm{WO}_{3}$ films and their electrochromic characteristics," J. Phys. D, Appl. Phys., vol. 43, no. 28, pp. 285501-1-285501-6, 2010.

[35] F. Lin, J. Cheng, C. Engtrakul, A. C. Dillon, D. Nordlund, R. G. Moore, et al., "In situ crystallization of high performing $\mathrm{WO}_{3}$-based electrochromic materials and the importance for durability and switching kinetics," J. Mater. Chem., vol. 22, no. 1, pp. 16817-16823, 2012.

[36] Z. Jiao, J. Wang, L. Ke, X. Liu, H. V. Demir, M. F. Yang, et al., "Electrochromic properties of nanostructured tungsten trioxide (hydrate) films and their applications in a complementary electrochromic device," Electrochim. Acta, vol. 63, pp. 153-160, Feb. 2012.

[37] S. Sallard, T. Brezesinski, and B. M. Smarsly, "Electrochromic stability of $\mathrm{WO}_{3}$ thin films with nanometer-scale periodicity and varying degrees of crystallinity," J. Phys. Chem. C, vol. 111, no. 19, pp. 7200-7206, 2007.

[38] M. Deepa, A. K. Srivastava, K. N. Sood, and S. A. Agnihotry, "Nanostructured mesoporous tungsten oxide films with fast kinetics for electrochromic smart windows," Nanotechnology, vol. 17, no. 10, pp. 2625-2630, 2006.

[39] M. R. J. Scherer and U. Steiner, "Efficient electrochromic devices made from 3D nanotubular gyroid networks," Nano Lett., vol. 13, no. 7, pp. 3005-3010, 2013.

[40] Y. T. Park, Y. K. Hong, and K. T. Lee, "Characterization of electrochromic $\mathrm{WO}_{3}$ thin films fabricated by an RF sputtering method," J. Ceram. Process. Res., vol. 14, no. 3, pp. 337-341, 2013.

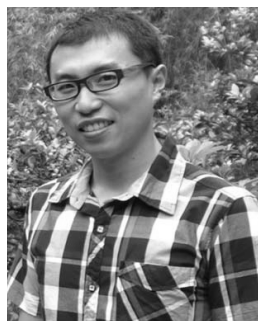

Chung Jung Hung received the B.S. and M.S degrees from the Department of Materials Science and Engineering, I-Shou University, Kaohsiung, Taiwan, in 2006 and 2008, respectively. $\mathrm{He}$ is currently pursuing the Ph.D. degree with the Department of Materials Science and Engineering, National Chiao-Tung University, Hsinchu, Taiwan.

His current research interests include the applications of electrochemistry in energy storage/conversion systems, fabrication of novel electrodes (oxide based electrode materials for supercapacitor), electrochromic technology (smart window), electrochemical engineering, and hydrothermal synthesis of metal oxide nanoparticles, and other unique electrophoretic technologies. 


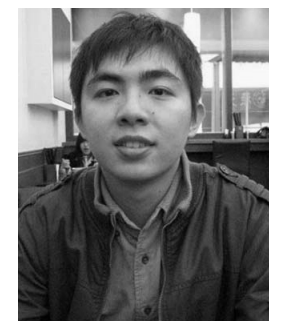

Yi Hsuan Huang received the B.S. degree from the Department of Electrical Engineering, Chang-Gung University, Taoyuan, Taiwan, and the M.S. degree from the Department of Electronic Engineering, National Chiao-Tung University, Hsinchu, Taiwan, in 2010 and 2012, respectively.

His current research interests include electrochromic technology (smart window) and hydrothermal synthesis of metal oxide nanoparticles.

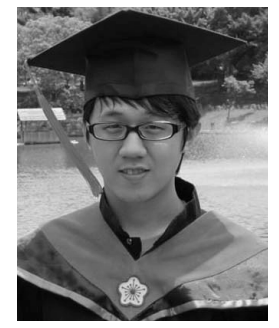

Chih Hao Chen received the B.S. degree from the Department of Physics, National Chung-Hsing University, Taichung, Taiwan, and the M.S. degree from the Department of Electronic Engineering, National Chiao-Tung University, Hsinchu, Taiwan, in 2011 and 2013, respectively.

His current research interests include electrochromic technology (smart window) and hydrothermal synthesis of metal oxide nanoparticles.

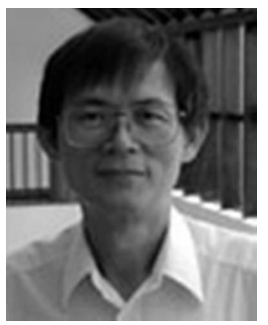

Pang Lin received the Ph.D. degree from the Department of Materials Science and Engineering, University of California, Los Angeles, CA, USA, in 1984.

$\mathrm{He}$ is a Professor with the Department of Materials Science and Engineering, National Chiao-Tung University, Hsinchu, Taiwan. His current research interests include semiconducting zinc oxide and energy materials.

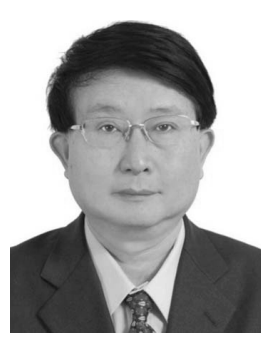

Tseung Yuen Tseng (F'02) received the Ph.D. degree in electroceramics from the School of Materials Engineering, Purdue University, West Lafayette, IN, USA, in 1982

He was with the University of Florida, Gainesville, FL, USA, before joining National Chiao-Tung University, Hsinchu, Taiwan, in 1983, where he is currently a Lifetime Chair Professor with the Department of Electronics Engineering and the Institute of Electronics. He was the Dean of College of Engineering from 2005 to 2007, the Vice Chancellor and University Chair Professor with the National Taipei University of Technology, Taipei, Taiwan, from 2007 to 2009. His current research interests include electronic ceramics, nanoceramics, ceramic sensors, high- $k$ dielectric films, ferroelectric thin films and their based devices, and resistive switching memory devices. He has published over 320 research papers in refereed international journals and 130 conference papers, several book chapters, and held 30 patents. He invented the base metal multilayer ceramic capacitors, which have become large scale commercial product.

Dr. Tseng is an Editor of Handbook of Nanoceramics and Their Based Nanodevices and Nonvolatile Memories: Materials, Devices, and Applications, Guest Editor of a special issue of Ferroelectrics (six volumes), an Associate Editor of the Journal of Nanoscience and Nanotechnology, Advanced Science Letters, and the International Journal of Applied Ceramic Technology. He is a Board Member of the Asia Ferroelectrics Association and General Chair of The Sixth Asian Meeting of Ferroelectrics. He is a Chairperson, Session Chair, Keynote and Invited Speaker, and Advisory Committee Member of many National and International meetings. He received the Distinguished Research Award from the National Science Council from 1995 to 2001 , the Hou Chin-Tui Distinguished Honor Award in 2002, the Dr. Sun Yat-Sen Academic Award in 2003, the TECO Technology Award in 2004, the IEEE CPMT Exceptional Technical Achievement Award in 2005, the Distinguished Research Award of Pan Wen Yuan Foundation in 2006, the Academic Award of Ministry of Education in 2006, the Medal of Chih-Hung Lu in 2010, the National Endowed Chair Professor in 2011, and the IEEE CPMT Outstanding Sustained Technical Contribution Award in 2012. He was a fellow of the American Ceramic Society in 1998, and MRS-T Fellow in 2009. 